\title{
Coagulation activation, depletion of platelet granules and endothelial integrity in case of uraemia and haemodialysis treatment
}

\author{
Marianne Schoorl ${ }^{1 *}$, Margreet Schoorl ${ }^{1}$, Menso J Nubé $^{2}$ and Piet CM Bartels ${ }^{1}$
}

\begin{abstract}
Background: During haemodialysis (HD) treatment, increase of platelet (PLT) activation and induction of procoagulant activity is demonstrated. Although the role of the endothelium and its direct interaction with coagulation and homeostasis is known, it is not elucidated how PLT activation markers and activation of coagulation coincide with markers of endothelial integrity during HD treatment. In the present study uraemia and HD induced changes, with particular emphasis on PLT granules depletion, activation of coagulation and endothelial integrity were investigated.

Methods: To detect depletion of PLT granules, peripheral blood slide smears were screened by light microscopy for qualitative evaluation of PLT granule containing cytoplasm, as indicated by its granules staining density. Activation of coagulation was investigated by establishement of thrombin-antithrombin (TAT) and fibrinogen concentrations. To evaluate endothelial integrity proendothelin (proET-1) plasma concentrations were established.

Results: Results of our study demonstrate that proET-1 plasma concentrations were obviously increased in the subjects' group with end-stage chronic kidney disease (CKD) and renal failure if compared with a group of apparently healthy subjects. The amount of depleted PLT granules was obviously increased in the subjects' group with end-stage CKD if compared with the group with renal failure. Mean plasma concentrations of TAT and fibrinogen revealed results within the reference range.

Conclusions: It is demonstrated that uraemia is associated with endothelial damage and aberrations in PLT granules morphology in subjects with HD treatment. We hypothesize that increased proET-1 concentrations reflect ongoing stress on endothelial cells amongst others due to uraemia. Biomarkers like proET-1 and aberrations in PLT granules morphology assist in the early detection of procoagulant activity of the endothelium.
\end{abstract}

Keywords: Platelet granules depletion, Coagulation, Proendothelin, End-stage kidney disease, Renal failure

\section{Background}

Subjects with chronic kidney disease (CKD) are at risk of cardiovascular diseases and suffer from accelerated atherosclerosis $[1,2]$. Maintaining the functional integrity of the endothelium is important in prevention or delay of vascular diseases [3].

The vascular endothelium plays a pivotal role in the modulation of vascular tone, initiation of coagulation, fibrinolysis activity and release of inflammatory mediators [4].

\footnotetext{
* Correspondence: m.i.schoorl@mca.nl

'Department of Clinical Chemistry, Haematology \& Immunology, Medical Center Alkmaar, Alkmaar, The Netherlands

Full list of author information is available at the end of the article
}

The endothelium of subjects with CKD is continuously exposed to uraemic toxins. These toxins are classified in three groups: water-soluble compounds with low molecular weight, such as urea, middle molecular weight substances and protein-bound uraemic toxins [5]. Proteinbound uraemic toxins are poorly eliminated by haemodialysis (HD) treatment. Systemic exposure of the endothelium to uraemic toxins may lead to activation of the endothelial cells and to features associated with systemic inflammation like hypertension and atherosclerosis [6,7]. However, the mechanisms by which increased uraemia might influence activation of endothelial cells have not been elucidated.

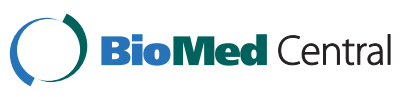


Intact endothelium demonstrates anticoagulant activity [8]. An essential function of endothelium is to provide an anti-thrombotic surface which inhibits activation of the coagulation cascade [8]. Bacterial endotoxins or inflammatory cytokines, such as IL-1, and glycosylated proteins are able to activate endothelial cells [8]. Activated endothelium has procoagulant properties and promotes coagulation. Tissue factor originating from the endothelium plays an important role in the transformation of anticoagulant endothelium to procoagulant endothelium $[8,9]$. Agonists capable of inducing release of tissue factor include thrombin, endotoxins, cytokines, hypoxia, shear stress and oxidized lipoproteins. Shear stress and metabolic stimuli, in particular complement, granulocytes, platelets and free radicals, induce secretion of endothelin-1 (ET-1) and endothelial cell deterioration [10].

Subjects with end-stage CKD are on regular HD treatment for two or three times a week. Despite appropriate anticoagulation treatment, increase of platelet (PLT) activation and induction of procoagulant activity is demonstrated during HD treatment [11-14]. Thrombin is involved in the activation of PLTs, neutrophils and monocytes, and acts on endothelial cells in order to release vasoactive and inflammatory mediators [9].

Although the role of the endothelium and its direct interaction with coagulation and homeostasis is known, it is not elucidated how PLT activation markers and activation of coagulation interact with markers of endothelial integrity during HD treatment. In the current study we report on uraemia and HD induced changes, with particular emphasis on PLT granules depletion, activation of coagulation and endothelial integrity.

\section{Methods}

\section{Patients}

A group of 20 subjects with end-stage CKD (age 2882 years) from the Haemodialysis unit of the Medical Center Alkmaar participated in the study. Patients were on regular HD treatment for at least 1 year (median 30 months, range 12-80 months). The etiology of chronic renal insufficiency was hypertensive nephrosclerosis $(n=8)$, diabetic nephropathy $(\mathrm{n}=5)$, adult dominant polycystic kidney disease $(n=3)$, IgA nephropathy $(n=1)$, tubulo-interstitial nephritis $(n=1)$, chronic pyelonephritis $(n=1)$ and membranous nephropathy $(n=1)$. Criteria for exclusion were subjects with an age of $<18$ years, a life expectancy $<3$ months, active inflammation, thrombocytopenia, autoimmune disease or malignancy as well as supplementation of drugs interfering with PLT function or anticoagulation (immunosuppressive drugs, calcium antagonists, serotonin receptor antagonists, coumarin derivatives and salicylates). The study protocol was approved by the local Medical Ethical Committee (METC Noord-Holland, The Netherlands). Written informed consent was obtained from participants.
For the purpose of comparison and clinical interpretation with regard to the pathophysiological effects of uraemia, additional investigations were performed in a group of 20 subjects with renal insufficiency (aged 3685 years, GFR $<80 \mathrm{ml} / \mathrm{min}$ ).

A reference group of 20 subjects (laboratory technicians, aged $20-50$ years), was selected in order to establish reference range intervals for parameters reflecting activation of coagulation and endothelial integrity.

\section{Blood sampling}

During this study blood samples from the subjects' group on regular HD treatment were taken from the fistula $(\mathrm{t} 0)$ before the administration of LMWH.

For establishment of proendothelin-1 (proET-1) levels in plasma, blood samples were collected into $\mathrm{K}_{2}$ EDTAtubes (Vacutainer ${ }^{\circledR}$, Becton Dickinson, Plymouth, UK). Sodium citrate tubes $\left(0.109 \mathrm{Mol}\right.$, Vacutainer ${ }^{\circledR}$, Becton Dickinson, Plymouth, UK) were applicated for establishment of trombin-antitrombin (TAT) and fibrinogen plasma concentrations. Blood samples for determination of concentrations of proET-1, TAT and fibrinogen were centrifuged at $2-8^{\circ} \mathrm{C}$ for 20 minutes at $2500 \mathrm{~g}$ in order to separate plasma from the cellular fraction. Plasma aliquots were stored at $-70^{\circ} \mathrm{C}$ until analysis.

\section{Analytical methods \\ Morphology of PLT granules}

Peripheral blood slide smears were prepared in duplicate for evaluation of aberrations in the morphology of PLT granules. Slide smears were stained according to MayGrünwald-Giemsa methodology on a Sysmex SP-100 analyzer (Sysmex Corporation, Kobe, Japan). Slide smears were microscopically screened for qualitative evaluation of morphological PLT granules aberrations with application of a CellaVision ${ }^{\text {Tm }}$ DM96 analyzer (CellaVision AB, Lund, Sweden). As previously established, a staining density $>75 \%$ of the PLT granules containing cytoplasm in $>50 \%$ of PLTs was considered to be the lower limit of the reference range [15]. Depleted PLTs granules were defined as PLTs with a staining density amounting to $<25 \%$ of the PLT granules containing cytoplasm. The upper limit of the reference interval for depleted PLT granules was determined at $<20 \%$ of PLTs [15].

\section{TAT, fibrinogen and proET-1 plasma concentration}

TAT plasma concentrations were assayed with ELISA (Enzygnost $^{\circledR}$ TAT micro and Enzygnost ${ }^{\circledR} \mathrm{F} 1+2$ monoclonal, Siemens Healthcare Diagnostics Inc., Marburg, Germany). ProET-1 concentrations were established by means of a commercial LIA-kit (B.R.A.H.M.S. CT-proET-1, B.R.A.H.M.S. AG, Hennigsdorf, Germany). Fibrinogen concentrations were established on a ACL-TOP analyzer (Instrumentation Laboratory, Milan, Italy) in accordance 
with the Clauss method by adding excess of thrombin to diluted plasma in order to convert fibrinogen to fibrin (Instrumentation Laboratory, Milan, Italy).

\section{Statistical evaluation}

Statistical evaluation of data was performed with application of SPSS software 14.0 for Windows. Statistical significance of deviations between mean values of the group of HD subjects and the group with renal failure and the reference group of laboratory technicians was established by applying the one-way analysis of variance (one-way ANOVA). A p-value $<0.05$ was considered to be statistically significant. Correlation coefficients (r) were calculated and expressed as Pearson's coefficients.

\section{Results}

Mean results for the groups of subjects with end-stage CKD and renal insufficiency together with the results of the reference group of laboratory technicians are depicted in the Figures 1, 2 and 3. Plasma concentrations of proET1 are demonstrated in Figure 1. Results for parameters reflecting aberrations in the morphology of PLT granules are demonstrated in Figure 2. Results for parameters concerning activation of coagulation (TAT and Fibrinogen) are demonstrated in Figure 3.

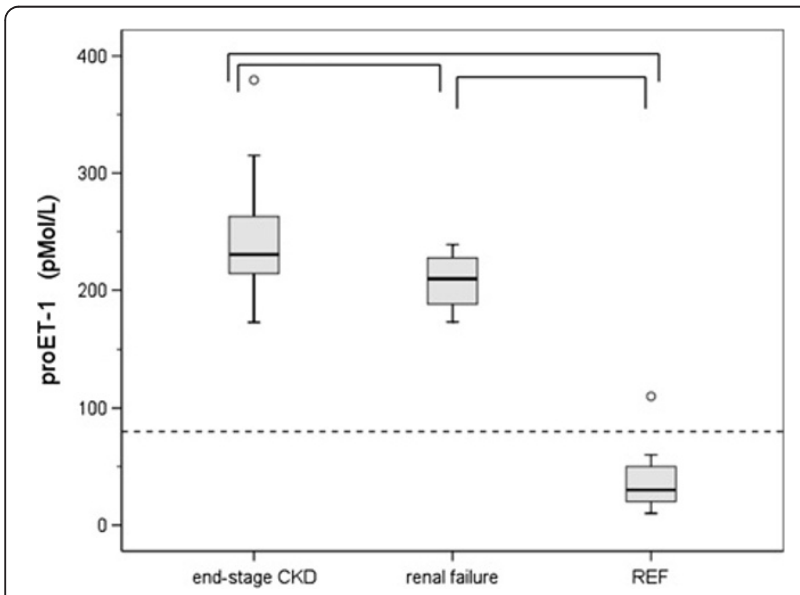

Figure 1 Biomarker ProET-1 concentrations. Box plots representing proET-1 concentrations established in subjects with end-stage CKD $(n=20)$ and renal failure $(n=20)$. For comparison, results for a group of 20 apparently healthy subjects (REF) are depicted. The box extends form the $25^{\text {th }}$ to the $75^{\text {th }}$ percentile. The line inside the box indicates the median value. Whiskers extend to the largest and smallest observed values within 1.5 box lengths. Outlying values corresponding with values between 1.5 and 3 times the box length are designated as (0). The horizontal dashed line indicates the upper level of the reference range for apparently healthy subjects. Statistically significant deviations between groups $(p<0.05)$ are indicated by $\Pi$

\section{proET-1}

ProET-1 concentrations in subjects with end-stage CKD (mean $\pm \mathrm{SD}$ ) amounted to $244 \pm 47 \mathrm{pMol} / \mathrm{L}$. One-way Anova statistics revealed a positive correlation regarding the reference group and the groups with renal insufficiency and end-stage CKD ( $\mathrm{p}=0.000)$. ProET-1 concentrations in the subjects with end-stage CKD $(207 \pm 23$ $\mathrm{pMol} / \mathrm{L}, \mathrm{p}=0.017$ ) were significantly increased in comparison with subjects with renal insufficiency. ProET-1 results for both groups were obviously increased in comparison with the reference group of apparently healthy subjects $(37 \pm 22 \mathrm{pMol} / \mathrm{L})$ (Figure 1$)$. In $45 \%$ of the subjects with end-stage CKD proET-1 concentrations were above $250 \mathrm{pMol} / \mathrm{L}$ (Table 1).

\section{Morphology of PLT granules}

In the group of reference subjects $70 \pm 12 \%$ of the PLTs are established to reveal appropriate staining density of the PLT granules. In subjects with chronic HD treatment staining density of the granule containing PLT cytoplasm decreased to a minimum score (Figure 2). Only $19 \pm 10 \%$ of the PLTs yielded $>75 \%$ PLT granules staining density $(\mathrm{p}=0.000)$. Subjects with renal failure showed also a marked decrease of the PLTs with appropriate staining density of the PLT granules $(43 \pm 12 \%$, $\mathrm{p}=0.000)$.

PLTs with a staining density amounting to $<25 \%$ of the PLT granules containing cytoplasm are classified as depleted. In the reference subjects' group only $9 \pm 6 \%$ of the PLTs reveal depleted PLT granules $(\mathrm{p}=0.000)$ (Figure 2). In the subjects' group with end-stage CKD $46 \pm 11 \%$ of the PLTs reveal depleted granules staining. In the subjects' group with renal failure $25 \pm 6 \%$ of the PLTs reveal depleted granules staining.

\section{TAT, fibrinogen}

TAT plasma concentrations and fibrinogen concentrations in the group with end-stage CKD and renal failure are demonstrated in Figure 3. One-way Anova statistics revealed a positive correlation regarding the reference group and the groups with renal insufficiency and endstage CKD $(p=0.010)$. Mean results for TAT and fibrinogen concentrations in the group with end-stage CKD were within the reference range and did not statistically differ from the results of the reference group. However, in the group with end-stage CKD increased TAT or fibrinogen concentrations were established in respectively $15 \%$ and $40 \%$ of the subjects.

Statistically significant increases for fibrinogen and TAT concentrations were established in the subjects with renal failure in comparison with the reference group $(\mathrm{p}=0.000)$, whereas only TAT results differ significantly from the results of the group with end-stage CKD $(\mathrm{p}=0.014)$. 

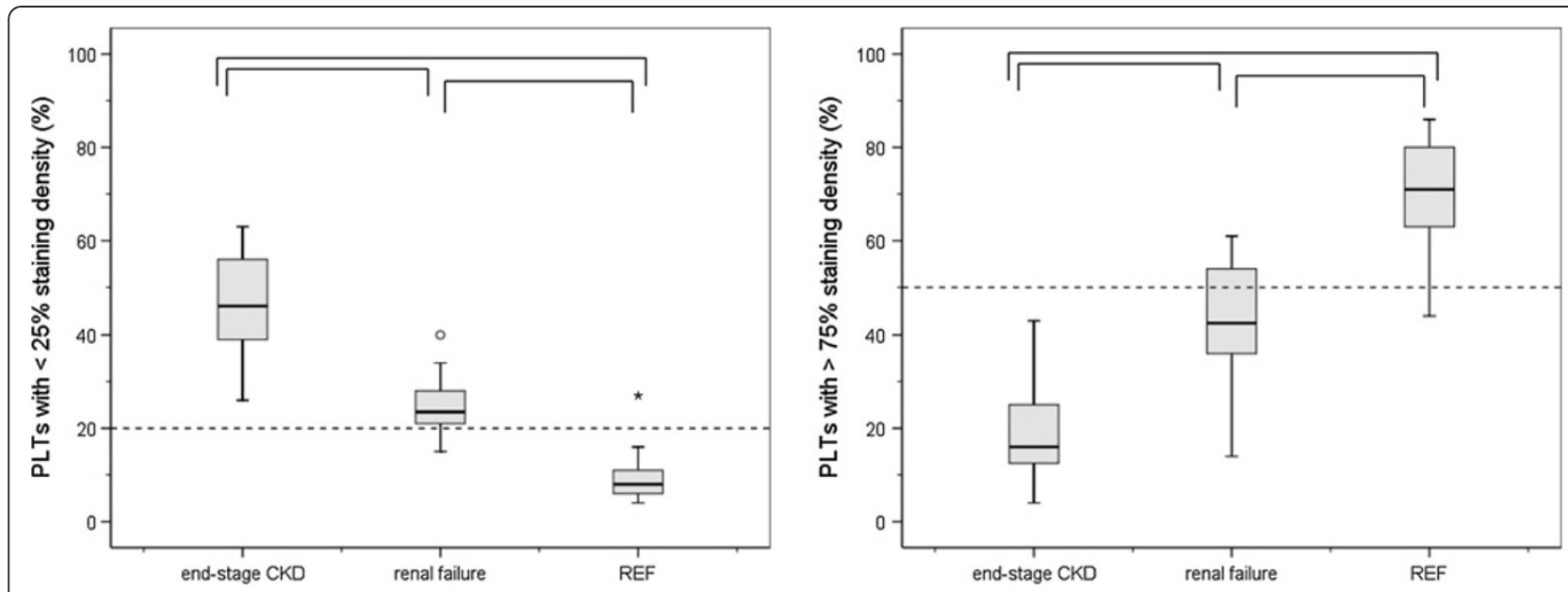

Figure 2 PLT granules staining density. Box plots representing the percentage of PLTs with $<25 \%$ (left)) and $>75 \%$ (right) staining intensity of the granules containing cytoplasm established in subjects with end-stage CKD $(n=20)$ and renal failure $(n=20)$. For comparison, results for a group of 20 apparently healthy subjects (REF) are depicted. The box extends form the $25^{\text {th }}$ to the $75^{\text {th }}$ percentile. The line inside the box indicates the median value. Whiskers extend to the largest and smallest observed values within 1.5 box lengths. Outlying and extreme values corresponding with values between 1.5 and 3 times the box length or $>3$ times the box length, respectively, are designated as $(0)$ and $(*)$. The horizontal dashed lines indicate the upper (left) and lower (left) level of the reference range for apparently healthy subjects. Statistically significant deviations between groups $(p<0.05)$ are indicated by $\prod$.

\section{Correlation between proET-1 and modifications in PLT morphology or markers indicating activation of coagulation}

Establishment of the interdependence of proET-1 results with additional parameters reflecting aberrations in the morphology of PLT granules reveal a negative correlation with PLTs with appropriate PLT granules staining density $\mathrm{r}=-0.84, \mathrm{p}=0.000$ (Figure 4 ).
For results concerning activation of coagulation a similar correlation is detected (Table 2). A statistically significant positive correlation to increased values for proET-1 with TAT and fibrinogen has been established in the group of reference subjects and the subjects groups with renal failure and end-stage CKD of $\mathrm{r}=0.34(\mathrm{p}=0.016)$ and $\mathrm{r}=0.31(\mathrm{p}=0.028)$ respectively (Table 2).

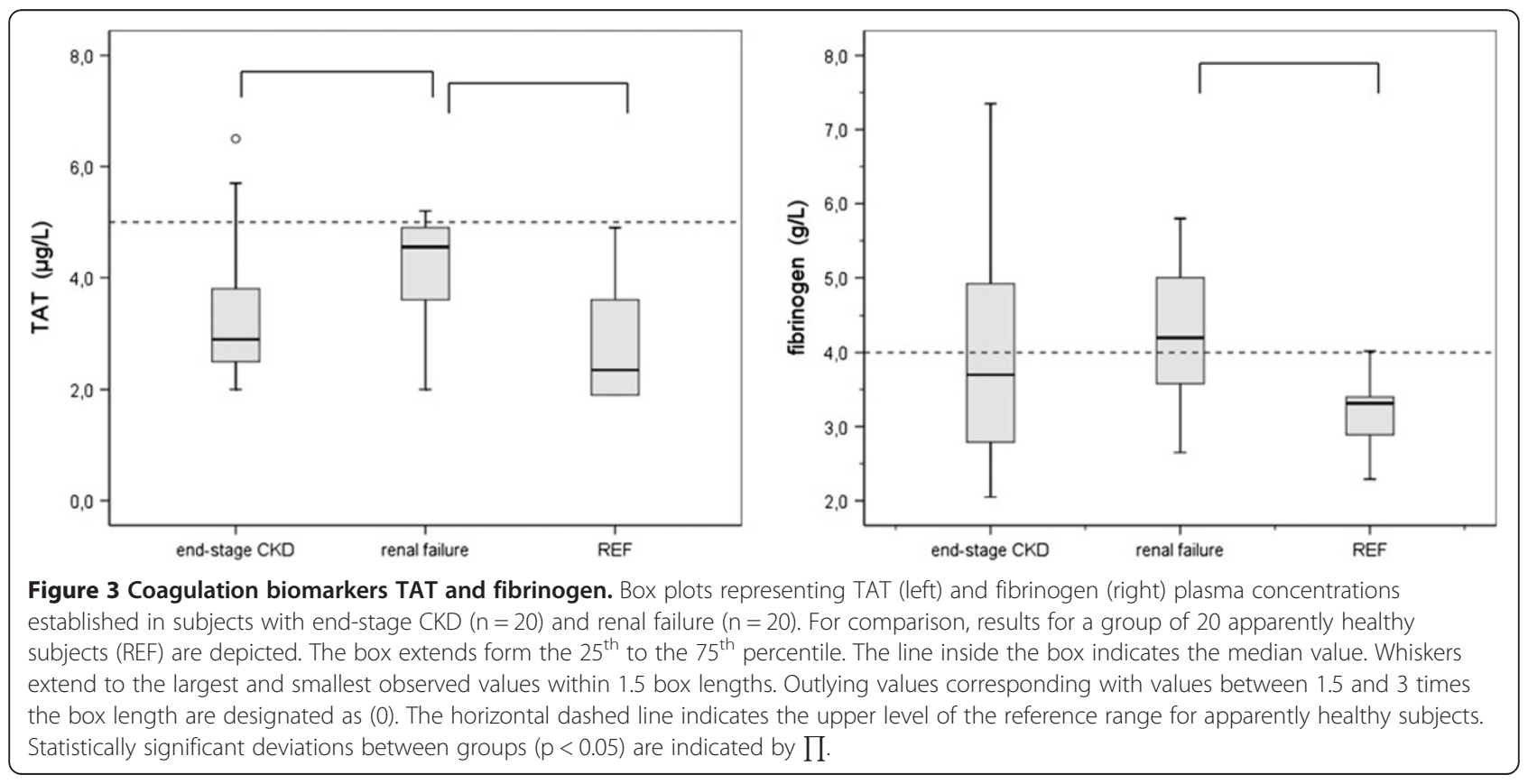


Table 1 PLT granules staining density and coagulation activation parameters in end-stage CKD subjects with proET-1 concentrations of $<250$ and $>250 \mathrm{pMol} / \mathrm{L}$

\begin{tabular}{lccc}
\hline & \multicolumn{3}{c}{ End-stage CKD } \\
\hline & $\begin{array}{c}\text { proET-1 }<250 \\
\text { pMol/L }(n=11) \\
\text { mean } \pm \text { SD }\end{array}$ & $\begin{array}{c}\text { proET-1 }>250 \\
\text { pMol/L }(n=9) \\
\text { mean (SD) }\end{array}$ & $\begin{array}{c}\text { statistical } \\
\text { significance }\end{array}$ \\
$\begin{array}{l}\text { proET-1 (pMol/L) } \\
\text { PLTs with <25\% }\end{array}$ & $33 \pm 18$ & $285 \pm 40$ & $\mathrm{p}=0.000$ \\
$\begin{array}{l}\text { granules staining } \\
\text { density (\%) }\end{array}$ & & $46 \pm 8$ & $\mathrm{p}=0.008$ \\
$\begin{array}{l}\text { PLTs with }>75 \% \\
\text { granules staining } \\
\text { density (\%) }\end{array}$ & $34 \pm 15$ & $18 \pm 10$ & $\mathrm{p}=0.001$ \\
$\begin{array}{l}\text { TAT ( } \mu \mathrm{g} / \mathrm{L}) \\
\text { Fibrinogen }(\mathrm{g} / \mathrm{L})\end{array}$ & $3.8 \pm 1.0$ & $3.8 \pm 1.4$ & $\mathrm{NS}$ \\
\hline
\end{tabular}

Evaluation of proET-1, PLT granule staining density, TAT and fibrinogen (mean value with standard deviation) established in the group with end-stage CKD. Results of statistically significant evaluation are indicated as p-values. $\mathrm{NS}=$ deviation not statistically significant.

Nine patients $(45 \%)$ of the subjects' group with endstage CKD yielded proET-1 concentrations exceeding $250 \mathrm{pMol} / \mathrm{L}$ (Table 1). Results for aberrations in the morphology of PLT granules in the subjects' group with proET-1 concentrations exceeding $250 \mathrm{pMol} / \mathrm{L}$ demonstrated statistically significant deviations if compared with the subjects' group with proET-1 concentrations

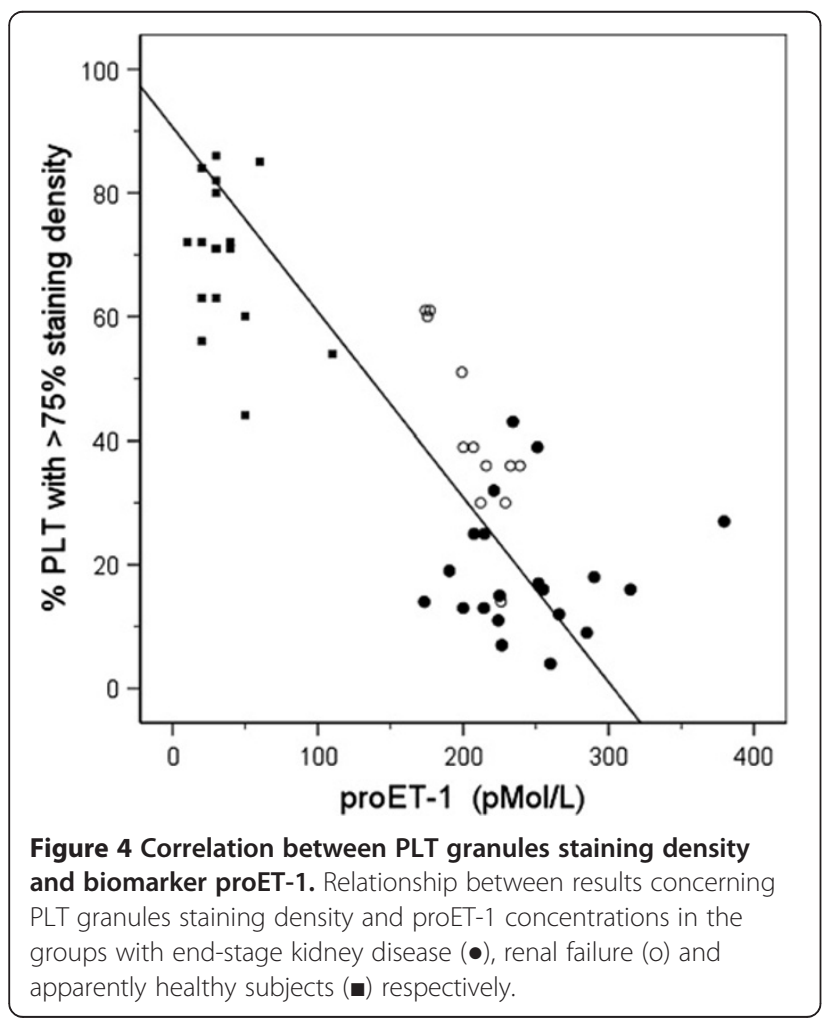

Table 2 Pearson correlation coefficients ( $r$ ) and statistical significance $(p)$ between biomarker proET-1, PLT granules staining density and biomarkers indicating activation of coagulation

\begin{tabular}{lcc}
\hline & $\begin{array}{c}\text { Pearson } \\
\text { correlation }(\mathbf{r})\end{array}$ & $\begin{array}{c}\text { Statistifical } \\
\text { significance }\end{array}$ \\
\hline $\begin{array}{l}\text { proET-1 and PLTs with }<25 \% \\
\text { granules staining density }\end{array}$ & 0.79 & $\mathrm{p}=0.000$ \\
$\begin{array}{l}\text { proET-1 and PLTs with }>75 \% \\
\text { granules staining density }\end{array}$ & -0.84 & $\mathrm{p}=0.000$ \\
proET-1 and TAT & 0.34 & $\mathrm{p}=0.016$ \\
proET-1 and Fibrinogen & 0.31 & $\mathrm{p}=0.028$ \\
\hline
\end{tabular}

below $250 \mathrm{pMol} / \mathrm{L}$, whereas markers for activation of coagulation did not differ (Table 1).

\section{Discussion}

ProET-1 plasma concentrations in subjects with endstage CKD and renal failure were investigated for a possible association between reduced endothelial integrity and aberrations in the morphology of PLT granules or markers indicating activation of coagulation.

The in vivo inactive biomarker proET-1 reflects the level of the bioactive peptide ET-1. ProET-1 is the precursor of ET-1, which reveals stability ex vivo [16]. Results of the study demonstrate that ProET-1 plasma concentrations are obviously increased in the subjects' group with end-stage CKD and renal failure if compared with a group of apparently healthy subjects. Results are in accordance with the findings of other authors, who demonstrated increasing endothelin plasma concentrations with progression of renal failure $[17,18]$. Altered expression of microcirculation parameters with age is a commonly occurring phenomenon. In the age of 25 till 65 years concentrations of proET-1 increase by $20 \%$ [16]. However, on the basis of age related shifts, the increase in proET-1 concentrations in the groups with end-stage CKD and renal failure are obviously higher than expected. ProET-1 plasma concentrations in the subjects' group with end-stage CKD demonstrate a statistically significant increase if compared with the subjects' group with renal insufficiency. Endothelial injury is considered to initiate increased secretion of ET-1 and to effectuate vasoconstriction, increased intraglomerular pressure, and decreased glomerular filtration [17]. ET-1 concentrations are demonstrated to correlate with blood pressure, suggesting that ET-1 may contribute to hypertension [18]. Reduced endothelial integrity is considered to be associated with increased incidence of cardiovascular disease [17]. Together with inflammation, hyperhomocysteinaemia and anaemia, cardiovascular disease yields an additional risk factor in subjects with end-stage CKD [19].

Moreover, results of our study demonstrate that the amount of depleted PLT granules is obviously increased 
in the subjects' group with end-stage CKD if compared with the group with renal failure. Subjects with endstage CKD are on regular HD-treatment. Pathophysiological mechanisms inducing activation of coagulation are based on Virchow's triad including modifications in vessel wall, blood flow and composition of blood components [20-22]. During HD treatment, blood constituents interact with the foreign surfaces within the extracorporeal circuit (ECC), including the wall of blood lines, the artificial dialyzer membrane and mechanical forces of the roller pump. Within the ECC endothelium is lacking and activation of PLTs and biomarkers inducing activation of coagulation are released by mechanical triggers [23]. In order to prevent clotting in the ECC during HD, a bolus of low molecular weight heparin or unfractionated heparin is supplied at the start of each HD session. Despite appropriate anticoagulation treatment, the rather unphysiological conditions within the ECC, amplified by pre-dialysis increased uraemia related factors, induce PLT activation. Increase of PLT activation and procoagulant activity is demonstrated in HD patients $[24,25]$. PLTs are activated within the ECC, as detected by increase in the expression of CD62p and release of $\beta$-tromboglobulin ( $\beta$-TG) within the ECC [23]. PLT activation is associated with exposure of phosphatidylserine on the PLT exterior. Platelet factor-4 and $\beta$-TG are released from PLTs as a result of a defect in their granules membrane mainly as a consequence of the bloodmembrane contact during $\mathrm{HD}$ and return only slowly postdialytic to control values [26].

In this study mean concentrations of TAT and fibrinogen reveal results within the reference range. However, in the group with end-stage CKD increased TAT or fibrinogen concentrations are established in respectively $15 \%$ and $40 \%$ of the subjects, indicating activation of the coagulation pathway or an acute phase response already before the beginning of a new HD session. The inner negatively charged wall of the ECC induces activation of FXII and subsequently the intrinsic coagulation pathway. Increased concentrations of TAT as well as prothrombin fragment $1+2$ treatment during $\mathrm{HD}$ indicate that thrombin is generated [12-14]. Additionally, it has been demonstrated that thrombin is involved in the activation process of PLTs, neutrophils, and monocytes, and acts on endothelium in order to release a variety of vasoactive and inflammatory mediators [9].

With respect to different biomarkers of activation of PLTs and the coagulation pathway dissimilar results could be obtained. Although activation of PLTs and the coagulation pathway is present, concentrations of activation and release products staying within the reference values could also be detected as a result of different release times, presence of neutralizing agents and removal by the dialyzer membrane $[11,14]$.
Results of our study demonstrate that uraemia is associated with endothelial damage and aberrations in the staining density of PLT granules in subjects with CKD. Uraemic toxins, especially protein-bound toxins, are likely pathogenic agents inducing endothelial damage in CKD [27]. In case of renal failure, endothelial damage and cardiovascular complications like hypertension are closely linked $[28,29]$. Concerning interpretation of our experimental data, we hypothesize that increased proET1 concentrations reflect ongoing stress on the endothelium amongst others due to uraemia. Biomarkers like proET-1 and aberrations in the staining density of PLT granules contribute in the early detection of procoagulant activity of the endothelium. Therefore, the level of proET-1 concentration and the amount of depleted PLT granules will add an important link to the degree of endothelial integrity and the severity of CKD.

\section{Conclusions}

In this study it has been demonstrated that uraemia is associated with endothelial damage and aberrations in appropriate staining density of PLT granules in subjects with HD treatment. In subjects with end-stage CKD deterioration of integrity of the endothelium and depletion of PLT granules are aggravated, because of the frequent PLT activation in the ECC during HD treatment.

\section{Abbreviations \\ CKD: Chronic Kidney Disease; ET-1: Endothelin-1; HD: Haemodialysis; PLT: Platelet; TAT: Trombin-antitrombin.}

\section{Competing interest}

The authors have no financial or other competing interests.

\section{Authors' contributions}

MiS participated in the design of the study, analysis of laboratory parameters for platelet granules staining density, activation of coagulation and endothelial integrity and data interpretation and has written the manuscript. MgS participated in the analysis of laboratory parameters for platelet granules staining density and activation of coagulation and has read and approved the manuscript. MN participated in the design of the study, provided intellectual content of haemodialysis and importance of the work, helped with a draft version of the manuscript and has read and approved the manuscript. PB participated in the design of the study and design and data interpretation, provided intellectual content of platelet granules staining density, activation of coagulation and endothelial integrity and importance of the work, has critically revised the draft versions of the manuscript and gave final approval for the current manuscript.

\section{Author details}

${ }^{1}$ Department of Clinical Chemistry, Haematology \& Immunology, Medical Center Alkmaar, Alkmaar, The Netherlands. ${ }^{2}$ Department of Nephrology, VU Medical Centre, Amsterdam, The Netherlands.

Received: 1 November 2012 Accepted: 15 March 2013

Published: 27 March 2013

\section{References}

1. Parfrey PS, Foley RN: The clinical epidemiology of cardiac disease in chronic renal failure. J Am Soc Nephrol 1999, 10:1606-1615.

2. Paul J, Dasgupta S, Ghosh MK, Shaw K, Roy KS, Niyogi SM: A study of atherosclerosis in patients with chronic renal failure with special 
reference to carotid artery intima media thickness. Heart Views 2012, 13:91-96.

3. Perrins $C J$, Bobryshev $\mathrm{W}$ : Current advances in understanding of immunopathology of atherosclerosis. Virchows Arch 2011, 458:117-123.

4. Martin BJ, Anderson TJ: Risk prediction in cardiovascular disease: the prognostic significance of endothelial dysfunction. Can J Cardiol 2009, 25:15A-20A.

5. European Uremic Toxin Work Group (EUTox), Vanholder R, DeSmet R, Glorieux G, Argilés A, Baurmeister U, Brunet P, Clark W, Cohen G, De Deyn PP, Deppisch R, Descamps-Latscha B, Henle T, Jörres A, Lemke HD, Massy ZA, PasslickDeetjen J, Rodriguez M, Stegmayr B, Stenvinkel P, Tetta C, Wanner C, Zidek W: Review on uremic toxins: classification, concentration, and interindividual variability. Kidney Int 2003, 63:1934-1943.

6. Costa E, Rocha S, Rocha-Pereira P, Castro E, Reis F, Teixeira F, Miranda V, Do Sameiro Faria M, Loureiro A, Quintanilha A, Belo L, Santos-Silva A: Cross-talk between inflammation,coagulation/fibrinolysis and vascular access in hemodialysis patients. J Vasc Access 2008, 9:248-253.

7. Jourde-Chice N, Dou L, Cerini C, Dignat-George F, Vanholder R, Brunet $P$ : Protein bound toxins-update 2009. Simin Dial 2009, 22:334-339.

8. Limaye $V$, Vadas $M$ : The vascular endothelium: structure and function. In Mechanisms of vascular disease: a textbook for vascular surgeons. Edited by Fitridge R, Thompson M. New York: Cambridge University Press; 2007:1-13.

9. Cardigan RA, Mackie IJ, Machin SJ: Hemostatic-endothelial interactions: a potential anticoagulant role of the endothelium in the pulmonary circulation during cardiac surgery. J Cardiothorac Vasc Anesth 1997, 11:329-336.

10. Ventetuolo CE, Levy MM: Biomarkers: diagnosis and risk assessment in sepsis. Clin Chest Med 2008, 29:591-603.

11. Grooteman MP, Bartels PC, Gritters-van den Oever M, et al: Post-dilution haemodiafiltration and low-flux haemodialysis have dissimilar effects on platelets: a side study of CONTRAST. Nephrol Dial Transplant 2009, 24:3461-3468

12. Bartels PCM, Schoorl M, Schoorl M, Wiering JGA, Nubé MJ: Activation of coagulation during treatment with haemodialysis. Scand J Clin Lab Invest 2000, 60:283-290.

13. Bartels PC, Schoorl M, Schoorl M, Nube MJ: Deviations in coagulation activation due to treatment with different haemodialysis membranes. Scand J Clin Lab Invest 2003, 63:417-424.

14. Schoorl M, Schoorl M, Nub MJ, Bartels PC: Platelet depletion, platelet activation and coagulation during treatment with hemodialysis. Scand J Clin Lab Invest 2011, 71:240-247.

15. Schoorl M, Schoorl M, Bartels PCM: Changes in platelet volume, morphology and RNA content in subjects treated with haemodialysis. Scand J Clin Lab Invest 2008, 68:335-342.

16. Papassotiriou J, Morgenthaler NG, Struck J, Alonso CV, Bergmann A: Immunoluminometric assay for measurement of the C-terminal endothelin-I precursor fragment in human plasma. Clin Chem 2006, 52:1144-1151.

17. Tomić M, Krešimir G, Markota I: Endothelin-1 and nitric oxide in patients on chronic haemodialysis. Ren Fail 2008, 30:836-842.

18. El-Shafey EM, El-Nagar EGF, Selim EM, El-Sorogy HA, Sabry AA: Is there a role for endothelin-1 in the hemodynamic changes. Clin Exp Nephrol 2008, 12:370-375

19. Zoccali C: Endothelial damage, asymmetric dimethylarginine and cardiovascular risk in end-stage renal disease. Blood Purif 2002, 20:469-472.

20. Lowe GDO: Virchow's triad revisited: abnormal flow. Pathophysiol Haemost Thromb 2004, 33:455-457.

21. Chung I, Lip GY: Virchow's triad revisited: blood constituents. Pathophysiol Haemost Thromb 2004, 33:449-454.

22. Blann AD: How a damaged blood vessel wall contributes to thrombosis and hypertension. Pathophysiol Haemost Thromb 2004, 33:445-448.

23. Gritters-Van Den Oever M, Schoorl M, Schoorl M, Bartels PCM, Grooteman MPC, Nubé MJ: The role of the extracorporeal circuit in the trapping and degranulation of platelets. Blood Purif 2009, 28:253-259.

24. Gritters M, Borgdorff P, Grooteman MPC, Schoorl M, Schoorl M, Bartels PCM, Tangelder GJ, Nubé MJ: Reduction in platelet activation by citrate anticoagulation does not prevent intradialytic hemodynamic instability. Nephron Clin Pract 2007, 106:c9-c16.

25. Schoorl M, Schoorl M, Bartels PCM: Platelet activation and serotonin release during treatment with haemodialysis. Ned Tijdschr Klin Chem Labgeneesk 2006, 31:236-238.
26. Elshamaa MF, Elghouroury EA, Hely A: Intradialytic and postdialytic platelet activation, increased platelet phosphatidylserine exposure and ultrastructural changes in platelets in children with chronic uremia. Blood Coagul Fibrinolyis 2009, 20:230-239.

27. Raff AC, Meyer TW, Hostetter TH: New insights into uremic toxicity. Curr Opin Nephrol Hypertens 2008, 17:560-565.

28. Perticone F, Maio R, Perticone M, Sciacqua A, Shehaj E, Naccarat P, Sesti G: Endothelial dysfunction and subsequent decline in glomerular filtration rate in hypertensive patients. Circulation 2010, 122:379-384.

29. Zoccali C, Maio R, Tripepi G, Mallamaci F, Perticone F: Inflammation as a mediator of the link between mild to moderate renal insufficiency and endothelial dysfunction in essential hypertension. J Am Soc Nephrol 2006, 17:S64-S68.

doi:10.1186/1471-2369-14-72

Cite this article as: Schoorl et al: Coagulation activation, depletion of platelet granules and endothelial integrity in case of uraemia and haemodialysis treatment. BMC Nephrology $201314: 72$.

\section{Submit your next manuscript to BioMed Central and take full advantage of:}

- Convenient online submission

- Thorough peer review

- No space constraints or color figure charges

- Immediate publication on acceptance

- Inclusion in PubMed, CAS, Scopus and Google Scholar

- Research which is freely available for redistribution

Submit your manuscript at www.biomedcentral.com/submit
C) Biomed Central 